\title{
Twitter for Educational Activities in Islamic Higher Education, Why Not?
}

\author{
Rully Agung Yudhiantara \\ E-mail:rully.agung@uinsgd.ac.id \\ UIN Sunan Gunung Djati Bandung
}

\begin{abstract}
This research was motivated by the need to combine the trend of using twitter among university students and the need of online educational activities. The study was aimed at investigating: twitter usage between Teacher and students for educational activities.2)discovering students perception on twitter usage for educational activities. This study found that twitter was used for educational activities by teacher and students. The activities occured namely; sharing information, asking and answering, and assigning task. In addition twitter was also used by student to save their document on learning process. Last findings showed that students perceived twitter in a positive manner and they appreciated twitter usage for educational activities.
\end{abstract}

Keywords: Educational Activities, Social Media, Twitter

\section{INTRODUCTION}

Sharing ideas, videos and other online activies are made easier by the existence of social networking like Youtube, twitter and facebook (Dieu \& Stephen, 2007). Social media is a current phenomenon in internet world. This 2.0 web-based application has attracted internet users worldwide. It offers internet users application that enables interaction among users worldwide. Not to mention the youth and teenagers who are born in this millenium, they belong to netizen who spend their daily in using social media. Popular phrase among expert to name this generation is native digital.

Social media influences the way internet users communicate. One of the feature that maintain social media existence is microblogging. There are some explanations concerning the the reasons why microblogging has maintained its popularity in web 2.0. in line with this Kaplan and Haenlein (2011) explain possible reasons as follows "(a) microblogging sites keep users updated about what is going on 
around them, (b) they allow users to read and share messages publically with greater ease than private social networking sites, and (c) they allow for both online exhibitionism and voyeurism for active microbloggers and passive readers (Kaplan \& Haenlein, 2011)

One of the application that applies microblogging is twitter. In a nutshell this application allows members to post 140-character messages to the public or people who follow a particular account. Once a user registers on a Twitter, other users can follow him or her; consequently whatever users shared is generally visible to all users who follow them. Twitter can be accessed not only through desktop but also through mobile phone. This shift in using gadget has generated millions of user to access twitter through their mobile phone (Yakin \& Tinmaz, 2013).

In a similar vein, Bozarth defines Twitter as "email 2.0". He elaborates in brief as follows " $A$ user can send a 140-character message (a tweet), forward other users' tweets (retweet), mark other users' tweets with the @ sign (tag), reply to tweets, send direct and private messages to other users, create lists of users, and publicly identify usernames in tweets by including the (a) sign (mentions) (Bozarth, 2010).

\section{Social Media Twitter and Educational Activities}

Internet and Education are two entities that complement each other. Internet has always offered educational activities new approach and media to deliver the service to students.. Many authentic sources are available to be used for teaching and learning ranging from audio, video and supplement of lesson. The emergence of social media has paved the way for language learning 2.0. opportunities to interact in a gnuine and authentic manner are possible by the existence of social media. Chartrand (2012) enthusiastically expresses "tasks that make use of Web 2.0 interactivity can significantly raise students' potential to generate meaningful output and stimulate their interest in language learning” (Chartrand, 2012)..

Internet advancement creates more options and applications for educational users. Social media which is microblogging in nature, has attracted educators worldwide. It has a great potential to be optimized as learning and teaching application. An ample studies have proven that 
a Web-based learning environment can promote constructivist learning through authentic activities related to the vast amount of information available on the Internet. Web-based learning enables to select and use material and tasks available in a combination of formats, such as text, graphics, audio, and video. Research have shown that these multimedia resources have great contribution in an effort to boost students' motivation (Woo, Herrington, Agostinho, \& Reeves, 2007).

Twitter has features that support teachers to accomplish teaching activities. As more concisely outlined by Nick Campbell (2009), Twitter can be applied in teaching and learning activities because twitter features four main advantages especially for teachers:1) Communicating class content, 2) Sending out small, timely pieces of information, 3) Encouraging collaboration and feedback and 4) Encouraging concise writing (Cambell, 2009)

\section{Previous Research on Twitter Usage for Educational Activities}

A study by Acar and Kimura (2012) was conducted to analyze how Japanese EFL learners use Twitter to study English. The study investigated the format of tweets, content of tweets, and the tweeting behavior. The study found that Japanese EFL learners post mostly greetings and daily-life related tweets and also frequently respond to other language learners' messages (Acar \& Kimura, 2012). Twitter facilitates interaction between student and students for educational purposesrs. A study by Fox and Varadajan showed that twitter facilitated learner-learner interaction. It also encouraged class participation, discussion, and attendance. However, they warned the negative effects of using twitter because sometime it is distracting or overwhelming (Fox \& Varadarajan, 2011).

Another study shows students usage of twitter for learning activities. This research was conducted by Ilker Yakin and Hasan Tinmaz (2013). it showed that the participants increased their uses of Twitter for learning purposes. Students idea about using twitter for learning improved. The study also warned about the possible negative effects of Twitter in instruction (Yakin \& Tinmaz, 2013). Twitter can 
be used for pedagogical use, communication concerning home work and assignment between teacher and students. This was proven in the study conducted by Cohen and Duchan (2012). The study showed that both the students and the teacher used twitter mainly for pedagogical uses, that is they communicated homework matter. Some questions and comments to intriguing issues were conducted in twitter and the result of discussion in twitter was brought up throughout the lessons in the classroom. In a nutshell this found that Twitter is an effective learning tool (Cohen \& Duchan, 2012).

A study conducted by M. C Ricoy and T. Feliz (2016) Considering the potential and popularity of social media it is important to inquire into its use in learning. They found that as students competence improved their motivation to use twitter increased. Students demanded that twiter be applied in teaching activities to enhance interaction between teacher students (Ricoy \& Feliz, 2016). Another study concerning student positive perception on twitter usage for educational activities was conducted by Tur and Marin (2015). They found that students expressed their positive perceptions towards the use of social media in education. the study also captured students' willingness for twitter future use in learning opportunities (Tur \& Marin, 2015) .

The previous studies reveal that twitter can be used for educational activities. It has positive impact on students' learning in general. As far as the studies concerned, there is a little research concerning twitter usage for educational activities conducted in indonesia. The gap becomes wider if the study is put in indonesian context of higher education, especially islamic higher education. This study fills in the gap. This study investigates the use twitter for educational activities in islamic higher education. It aimed to answer the following research questions: 1) How do Lecturer and Student use twitter for teaching and learning activities?, 2) How do Students perceive twitter use for teaching and learning activities?

\section{RESEARCH METHOD}

This study applied descriptive method which produces both exploratory and descriptive explanation (Hesse-Biber \& Leavy, 2006). 
(Hesse-Biber \& Leavy, 2006) It enables this study to describe and explain; the condition of the lecturer and students usage of twitter for teaching and learning activities; and students' perception on twitter usage. There were 40 students participating in this study. They belong to fourth semester of English Department UIN SGD Bandung. Teacher applied twitter usage outside classroom to support learning activities in classroom. to collect the data, this study demanded students to be active in using twitter for three months. Applying descriptive study, this research collected data through observation, document/ content analysis, and questionnaire. The data collected were analyzed through the following stages: describing, coding, categorizing, analyzing and interpreting.

\section{FINDINGS}

Findings in this study were categorized into two types namely :1) Teacher and students' usage of twitter for educational activities, 2)Students perception of twitter usage for educational activities.

\section{Twitter Usage for Educational Activities Among Teacher and Students}

Based on the observation, this study found that twitter application was used by many students in English Department in UIN. In other words many students had used twitter application before they participated in the study. Out of 40 students, there were 3 students who did not have twitter account. It was not difficult to conduct this study since most of students were familiar with the steps and direction of using twitter.

To describe in depth, this study found some educational activities conducted in twitter namely:

\section{a. Sharing Information between teacher and student}

Based on the observation, twitter was used by the teacher to inform many things. For example, teacher informed the students about preparation concerning materials to be discussed in the classroom.

Students gained information and they could prepare material they studied on a particular meeting. Here are examples of tweet between teacher and students. 
\#Session2. Dear students read chapter two. Find some difficult words from dictionary

\#Session2. Ok sir. Must we write the words and their meaning? Thank you sir

\section{b. Sharing information among students}

Based on the observation, twitter was used by students to discuss and share information concerning mterial in the classroom. This educational activities can be seen from the following tweet

\#session2 can anyone share the meaning for the word PRELUDE

@STUDENT1 PRELUDE Means something that happens before another event or activity

These tweet illustrated how interaction between students conducted in twitter. This interaction happened outside classroom and twitter facilitated this to happen.

\section{c. Saving file of learning process}

This study found that twitter facilitated students to store the document concerning the material they learned in the classroom. Students posted their tweet containing their understanding on the material they learned from a particular meeting. In organizing the tweet, teacher and students agreed to use hastag for each session during a semester.For example: \#UINBDG040216unit1. This tweet refers to: University code, date of session, and chapter of discussion.

The document of student language learning process can be easily administered. Since students were given those features and menus available in twitter, they produced tweet for each session and posted them in their account. Their posting were visible to their classroom mate because they follow each others account. One students posted the tweet using hastag as follows:

\#UINBDG040216unit1 this unit discuses topic on education. there are 9 paragraphs.

\#UINBDG040216unit1 main ideas of par 1 is the importance of education for human 
\#UINBDG040216unit1 vocabulries used in this unit; education, objective, teaching and learning Students also used hastag and posted tweet in response to a particular quiz and assignment given by the teacher. In a more detailed explanation, this situation can be described as follows; outside classroom session, lecturer posted a quiz concerning a particular chapter, and this tweet was visible to all the students' account. Next student produced tweet in their account and posted their answer by using the feature @ mention. It was a special feature that linked and enabled both user to exchange tweet.

The assignment given to student in twitter covered: vocabulary, grammar analysis, and reading comprehension. This online assignment was made possible by using twitter.

Examples of students document are as follows:

@ rullythegreat \#Quizunit1 summary of the text titled education. education plays important role in shaping and developing human index.

@ rullythegreat \#Quizunit1developed countries have spent their energy, budget to improve their education program.

\section{Students' Perception Concerning Twitter Usage for Educational Activities}

Based on the questionnaire given to students, this study found the data as follows:

\section{a. Obstacle in Operating Twitter}

In terms of twitter usage, some students found it difficult to operate twitter for the first time. The difficulties were experienced by students who had no previous experience in using twitter. They argued that the features available in twitter are different from the features available in facebook. It took time for them to be able to use the twitter. A student wrote in questionnaire as follows:

"It is difficult for me to operate twitter for the first time, because i have not any experience" 
Another difficulties experienced by students is the fact that twitter only allows 140 characters in producing a single tweet. This character was considered a challenge for students because they were required to be efficient in producing every single tweet to express their intention and ideas. A student wrote in uestionnaire as follows:

"to write a tweet consisting 140 characters is difficult. It is similar to write sms. Compared to other social application like facebook, this is a challenge"

\section{b. Advantages of Using Twitter}

Students admitted that they benefitted a lot from twitter usage for educational activities. Twitter is online social media in nature and it is possible to facilitate educational activities online. One student wrote as follows;

"I gained many advantages by using twitter for educational activities. I can share my understanding and material i learn. I can ask teacher and discuss with other students in twitter"

\section{c. Students' Suggestion on Twitter Usage for Educational Activities}

This study found that students supported the twitter usage for educational activities. Having gained the experience of using twitter, they began to see the prower of titer and its potential to be used for educational activities. A student wrote as follows;

"I believe twitter can be beneficial for educational activities, it helps student and teachers to maintain interaction in learning outside classroom"

\section{DISCUSSION}

In the finding section, this study has described data that aims to fulfill the objectives of the research. Those findings attempted to answer two research questions put forward in this study.

The findings have, to some extent, described the existing condition of lecturer and students usage of twitter for educational activities and students' perception on twitter usage in educational activities. 
Those findings show that twitter in this study has supported educational activities for both lecturer and students. Since twitter is online social media in nature, it enables the learning process outside classroom for both lecturer and students. The findings showed that the proces of educational activities occured in twitter which was online even though they were outside classroom. this activity supports the conventional classroom activities. The notion that using social media supports learning is in accordance with the social constructivism paradigm, which emphasizes social interaction and learning from others in the group.

Gadget or mobile phone is very common among students. This gadget helps students to stay connected through social media. This condition is in line with the notion of online learning. One of the possible way to implement it is by opting and implementing twitter for language learning process. In contrast, conventional classroom is limited by time and space for teacher and students interaction. No opportunities for them to extend the learning process outside classroom beyond their schedule. These support the previous findings that showed twitter is potential in increasing teacher-student and student-student dialogue (Jansen, Zhang, Sobel, \& Chowdury, 2009)

Students in this study used twitter to communicate among them. Some students asked teacher concerning a particular assignment. This findings are in line with the study conducted by Dunlap \& Lowenthal (2009). Since twitter is asynchrnous application, Twitter allows interaction both teacher student and student-students (Dunlap \& Lowenthal, 2009). In other words dialog occurs in twitter among teacher and students (Jansen, Zhang, Sobel, \& Chowdury, 2009)

The power of twitter which offers microblogging feature has been proven in this study. Students posted their learning process into tweet in their account. Hastag made it easier for students $t$ organize tweet and finally access the content that they posted and other students posted. 


\section{Storing Students' Learning Material Document}

This study found that students used twitter to document their learning process. The material learned in classroom were organzed and written then posted. To arrange these easily, students created hastag. it allows student to search easily what was being trending in a particular week concerning the material. Other studies by Athur and Conway (2012) using hastag to stimulate debate Twitter hashtags are normally used in classroom settings, for example, to expand debate about content or to ask questions (Arthur \& Conway, 2012)

Using hastag in storing students learning process indicate students' engagement in educational activities. Twitter increases learning engagement. This is in line with the previous study conducted by Evan (2014) that twitter boosted student engagement in learning (Evans, 2014).

Students perceived twitter as a positive and supporting tool that allowed them to interact and maintain communication. Their communication and interaction creates the sense of community. Student believed that twitter can build learning community. This finding supports the previous study that twitter helps learner to create a learning community ( (Jansen, Zhang, Sobel, \& Chowdury, 2009). This sense of community learning is fundamental to make sure that educational activities is carried out appropriately.

Students admitted that Twitter added joy to students in terms of learnng environment and it can be integrated in daily activities. Sharing knowledge among students was possible by using twitter. This advantages can be gained by using twitter (Bozarth, 2010).

Twitter helped students to gain material from teacher. In addition it increases the effectivenes of instruction. More tweets were posted concerning the material and assignment in twitter. Thi is in line with the previous study that twitter is potential to increase learning efectiveness (Dunlap \& Lowenthal, 2009)

Based on the findings, students supported the twitter usage for eductional activities. On the part of teachers, they must be able to suit the application and the need of classroom to attain succesful result of twitter in educational activities (Ricoy \& Feliz, 2016) 


\section{CONCLUSION}

Twitter is a potential social media that offers advantages if used approriatey in educational activities. This research was aimed at investigating how lecturer and students used twitter for educational activities, and how students perceived twitter usage for language learning process. Based on the findings and discussion above, this study concluded the following:

1. Lecturer and students used twitter to interact for educational activities. . In their interaction some activities which occured are as follows: sharing information between lecturer and students, asking and answering about task, discussing an assignment, storing their learning process concerning material, assignment .

2. Students expressed positive perception toward twitter usage in educational activities.

\section{REFERENCES}

Acar, A., \& Kimura, N. (2012). Twitter as a Tool for Language Learning: the Case of Japanese Learners of English. The Eighth International Conference on e-learning for Knowledge-Based Society (pp. 1-14). Thailand: International Journal of Computer, Internet, and Management.

Arnold, N., \& Paulus, T. (2010). Using Social Networking Site for Experiential Learning: Appropriating, Lurking, Modelling and Community Building. Internet and Higher Education, 188-196.

Arthur, J. M., \& Conway, K. B. (2012). Exploring the Relationship Between Student-Instructor Interaction on Twitter and Student Perception of Teacher Behavior. International Journal of Teaching and Learning in Higher Education, 286-292.

Borau, K., Ulrich, C., Feng, J., \& Shen, R. (2009). Microblogging for Language Learning. Using Twitter to Train Communicative and Cultural Competence. In M. S. al, Advances in Web-based Learning (pp. 78-87). Berlin, Germany: Springer.

Bozarth, J. (2010). Social Media for Trainers: Technique for Enhancing and Extending Learning. San Fransisco, CA: John Wiley and Sons, Inc. 
Bugeja, M. (2006). chronicle. Retrieved from http://chronicle.com/: http://chronicle.com/article/Facing-the-facebook/46904

Cambell, N. (2009, March 31). twitter for education. Retrieved September 6, 2009, from www.tienetwork.org: http://tienetwork.org/content/view/302

Chartrand, R. (2012). Social Networking for Language Learners: Creating Meaningful Output with Web 2.0 tools. International Journal Knowledge Management \& E-Learning, 97-101.

Chen, B., \& Bryer, T. (2012). Investigating Instructional Strategies for Using Social Media in Formal and Informal Learning. International Review of Research in Open and Distance learning, 87-104.

Cohen, A., \& Duchan, G. (2012). The Usage Characteristics of Twitter in the Learning Process. IJELLO interdisciplinary Journal of E-Learning and Learning Object.

Dieu, D., \& Stephen, V. (2007). Pedagogical Affordances of Syndication, Aggregation, and Mash-up. TESL-EJ, 1-15.

Dunlap, J., \& Lowenthal, P. (2009). Tweeting the Night Away: Using Twitter to enhance Social Presence. Journal of Information System Education, 1-8.

Evans, C. (2014). Twitter for Teaching: Can Social Media Be Used to Enhance the Process of Learning? British Journal of Educational Technology, 902-915.

Fox, B. I., \& Varadarajan, R. (2011). Use of Twitter to Encourage Interaction in a Multi-Campus Pharmacy Management Course. American Journal of Pharmaceutical Education, 1-8.

Hesse-Biber, S., \& Leavy, P. (2006). In the Practice of Qualitative Research. Thousand Oak: Sage.

Jansen, B. J., Zhang, M., Sobel, K., \& Chowdury, A. (2009). Twitter Power: Tweet As Electronic Word of Mouth. Journal of the American Society for Information Science and Technology, 2169-2188.

Jash, M. N. (2014). Tweeter a Technological Tool for English Language Learning. IMPACT international journal of Research in Humanities, Arts and Literature, 23-28. 
Java, A., Finn, T., Song, X., \& Tseng, B. (2007). Why We Twitter: Understanding Microblogging Usage and Communities. Proceeding of Joint 9th WEBKDD and 1st SNAKDD workshop 2007.

Kaplan, A. M., \& Haenlein, M. (2011). The Early Bird Catches the News: Nine Things You Should Know about Micro-blogging. Business Horizon, 105-113.

Lakarnchau, O. (2012). An Investigation of the Use of Microblogging by High and Low Proficiency Thai EFL Learners during the Completion of an English and Reading and Writing Assignment. Bangkok, Thailand: Chulalongkorn University.

Mork, C. M. (2009). Using Twitter in EFL Education. the JALT Call Journal, 41-56.

Noyes, D. (2015). Top 20 Valuable Facebook Statistics. Retrieved from https://zephoria.com/ social media/ top 15-valuablefacebook-statistics/

Ricoy, M. C., \& Feliz, T. (2016). Twitter as a Learning Community in Higher Education. Educational Technology and Society, 237248.

S. Zhao, S. G. (2008). Identity Construction on Facebook: Digital empowerment in Anchored Relationship. Computers in Human Behaviour, 1816-1836.

Tur, G., \& Marin, V. I. (2015). Enhancing Learners with the Social Media: Students' Teachers' Perception on Twitter in a Debate Activity. New Approaches in Educational Research, 46-53.

Woo, Y., Herrington, J., Agostinho, S., \& Reeves, T. (2007). Implementing Authentic Task in Web-based Learning Environment. Educause Quarterly, 36-43.

Yakin, I., \& Tinmaz, H. (2013). Using Twitter as an Instructional Tool: A Case Study in Higher Education. The Turkish Online Journal of Educational Technology, 209-218.

Yin, R. (2003). Case Study Research: Design and Method. Los Angeles: Sage Publication. 